\title{
Application of Archie Formula in Areas of Data Deficiencies
}

\author{
Bowen Qian ${ }^{1, ~ a ~}$, Rui Deng ${ }^{1, b^{*}}$, Bifang Lu ${ }^{1, c}$ and Weinan Liü ${ }^{2, d}$ \\ ${ }^{1}$ Key Lab of Exploration Technologies for Oil and Gas Resources, Ministry of Education (Yangtze \\ University), No. 111 Daxue Road, Caidian District, Wuhan 430100, China \\ ${ }^{2}$ School of Geophysics and Oil Resources, Yangtze University, No. 111 Daxue Road, Caidian \\ District, Wuhan 430100, China \\ aqianbwen@163.com, ’dunray@163.com, 'lu_bifang@163.com, 'liu_weinan95@163.com
}

Keywords: Logging Curve, Saturation Model, Archie Formula, Formation Factor, Resistivity Index Abstract. Based on the well logging data of the research area and the existing reservoir interpretation, Archie Formula is modified to work out the new saturation model which can be used to accurately calculate reservoir saturation when data of well log is incomplete. This paper introduces the general situation of research area and concludes the new saturation interpretation model by modifying Archie Formula according to characteristics of block, interpreting the 4 wells in research area in remarkably improved remarkably.

\section{Preface}

Research area situates at the middle of upthrown side of Du32 fault of middle part in the western slope in the western depression of Liaohe Basin, which is a monoclinal structure emerging in the slope and complicated by faults. The major oil reservoir, in ancient climate conditions which is alternate wet and dry and turbulent shore-shallow lake environment with shallow water body in the sedimentary stage. Main lithofacies types include inequigranular sandstone covering about $10.24 \%$, medium-fine sandstone about $8.44 \%$, fine sandstone about $21.69 \%$, clay-bearing inequigranular sandstone about $33.4 \%$, clay-bearing siltstone about $18.07 \%$, pelitic siltstone about $8.13 \%$.

In whole research area, the maximum of reservoir porosity is $35.4 \%$ with an average of $26.3 \%$; permeability maximum is $15.8 \mu \mathrm{m}^{2}$ with an average of $1.136 \mu \mathrm{m}^{2}$; maximum of carbonate content is $39.6 \%$ with an average of $12.19 \%$; maximum of clay content is $33.3 \%$ with an average of $12.19 \%$; Intensity median maximum is $0.64 \mathrm{~mm}$ with an average of $0.201 \mathrm{~mm}$. The sorting is uniform and the average of sorting coefficient is 1.79. Most wells in research area only have 7 curves including CAL, SP, RLLD, RLLS, RMN, RML, AC, which lead to data deficiency of well log and rock-electricity under the condition of high shale content. According to the actual situation of research area, the accuracy of saturation interpretation have been improved.

\section{Classic Archie's Formula}

According to the rock-electric experiment, Archie firstly put forward the relation formula between hydrocarbon reservoir resistivity and water saturation, that is Archie's Formula.

$$
I=\frac{R_{t}}{R_{0}}=\frac{1}{S w^{n}}
$$


As $R_{o}$ couldn't be measured directly under the reservoir condition, Archie established the relation between rock resistivity and rock porosity when filled with formation water. Accordingly rock resistivity when $100 \%$ full of formation water can be calculated by using rock porosity. Therefore, saturation interpretation model that can be directly adopted for reservoir evaluation reads.

$$
S_{W}=\sqrt[n]{\frac{a b R_{W}}{R_{t} \cdot \varphi^{m}}}
$$

The relation of reservoir rock resistivity and hydrocarbon saturation which was established by Archie Formula have laid the geological basis of well log interpretation for hydrocarbon reservoir. In Archie Formula, taking the ratio of $R_{t}$ and $R_{o}$ can eliminate the influence on the result caused by characteristic changes of some porosity and fluid, highlighting water saturation as the main factor.

In Formula (3-2), parameters (a, b, m, n), called as Archie parameters, are usually determined by rock-electric experiments. Due to the complexity of influence factors of reservoir rock electrical property, Mungan and Moore have analysed and pointed out that Archie Formula contains 3 implicit assumptions ${ }^{[2]}$, which include that 1 . the relation of saturation and resistivity shall be only; 2. for the given reservoir rock, $\mathrm{n}$ is constant; 3. all the formation water can conduct current.The above assumptions could be completely or approximately fulfilled only when rock physical property is good and hard to achieve if complex reservoirs, such as argillaceous sandstone or fractured reservoir, is encountered.

\section{The Modification of Archie Formula}

On account of various hysteresis effect, the relation of saturation and resistivity, not being only, shall also be concerned with saturation history and displacement method. Secondly, for the reservoir with strong heterogeneity, not all the formation water can conduct current due to the existence of trapping phenomenon. Therefore, it always presents rock electrical property in complex reservoir that Archie Formula can't describe, which is called Non-Archie Phenomenon. In order to implement saturation evaluation of complex reservoir, a series of extended Archie Formula have been developed in the course of practice.

We know that common saturation model is drawn from experiment research ${ }^{[6]}$.

$$
S_{W}=\sqrt[n]{\frac{a b R_{W}}{R_{t} \cdot \varphi^{m}}}
$$

In the model, $S_{w}$ denotes water saturation; denotes formation water resistivity; $R_{t}$ represents hydrocarbon pure rock resistivity; $\varphi$ represents effective porosity, a, b, $m$ and $n$ are coefficients. $R_{w}$ which requires many data to determine, can be replaced by these data that can be obtained easily or already known when there are no enough data to confirm $R_{w}$.

Iterative method is adopted to verify $R_{w}$ layer by layer in search of optimum value. Logging curve value that is used to replace $\mathrm{R}_{\mathrm{w}}$ shall accord with the changes of oil-water reservoir, remaining stable and with low occurrence of extraordinary large abnormal value. SP curve which is the only one related with the calculation of $R_{w}$ among the several curves, can distinguish oil-gas-water reservoirs as SP abnormal value of hydrocarbon reservoir is lower than that of water 
layer. Pure water layer, full of water and with pure rock property and large thickness own the largest SP abnormal value.

By editing program, taking into logging curve data, then calculating average value by layers and comparing with existed Logging interpretation conclusion, the below formula can be obtained:

$$
S_{w}=\sqrt[n]{\frac{1.0}{0.5 \Delta S P} / R_{\mathrm{t}}{ }^{\mathrm{m}}}
$$

Both $\mathrm{m}$ and $\mathrm{n}$ is 2.0 .

\section{The Application of Field Data}

Well X3 is a production well in research area whose porosity and permeability can be determined by conventional methods and whose saturation can be interpreted by using research model. Below is the interpretation Fig 1.

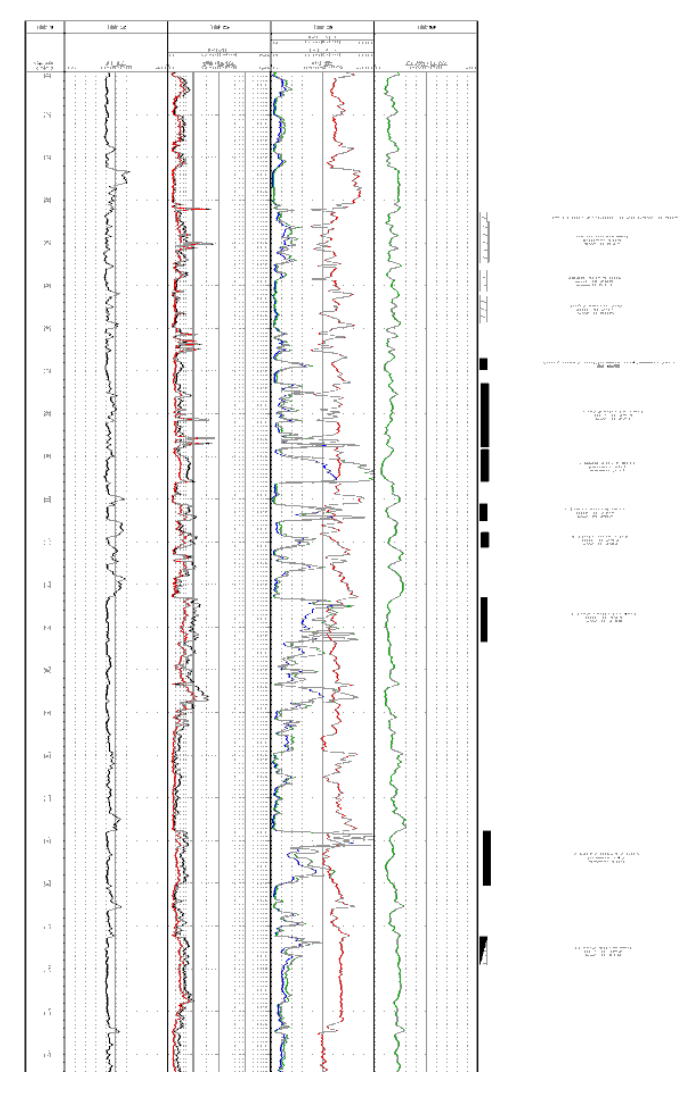

Fig. 1. X3 Well Logging Interpretation Result

In Well X3, there are 4 water layers whose porosity is in range of $18.4 \%-29.5 \%$ and water saturation is in range of 50.6\%-62.1\%; 7 heavy-oil layers whose porosity is in range of $25.2 \%-39.4 \%$ and water saturation is in range of $18.5 \%-29.4 \%$; an oil-water layer whose porosity is $38.2 \%$ and water saturation is $30.9 \%$.

It's seen from the logging curve data that deep lateral logging curve values of oil reservoir of this well area is very high. The porosity and water saturation can be seen from the below table 1 . 
Table 1. X3 Well Data Chart

\begin{tabular}{ccccc}
\hline Depth [m] & $\begin{array}{c}\text { Porosity } \\
{[\%]}\end{array}$ & $\begin{array}{c}\text { Water } \\
\text { Saturation } \\
{[\%]}\end{array}$ & $\begin{array}{c}\text { Interpreting } \\
\text { Conclusion }\end{array}$ & Right or Not \\
\hline $933.00-935.00$ & 28.3 & 50.6 & water layer & yes \\
$935.00-944.60$ & 18.4 & 62.1 & water layer & yes \\
$946.40-951.40$ & 29.5 & 61.3 & water layer & yes \\
$952.60-958.80$ & 25.7 & 60.6 & water layer & yes \\
$967.00-969.80$ & 30.4 & 28.3 & heavy-oil layer & yes \\
$972.80-987.80$ & 25.3 & 27.1 & heavy-oil layer & yes \\
$988.40-996.00$ & 35.1 & 23.1 & heavy-oil layer & yes \\
$1001.00-1005.00$ & 27.9 & 26.7 & heavy-oil layer & yes \\
$1007.80-1011.40$ & 25.2 & 29.4 & heavy-oil layer & yes \\
$1023.00-1033.40$ & 39.4 & 23.8 & heavy-oil layer & yes \\
$1077.80-1090.40$ & 34.2 & 18.5 & heavy-oil layer & yes \\
$1102.40-1109.00$ & 38.2 & 30.9 & oil-water layers & yes \\
\hline
\end{tabular}

4 wells and 68 layers of research area have been separately studied in accordance with the model discussed in the paper and after comparing with the data of oil testing and producing test, the accuracy rate is $95.59 \%$.

\section{Conclusion}

On the basis of Archie Formula and without the data of formation water resistivity to calculate water saturation in well logging interpretation, the paper analyses the feasibility of self-potential SP curve data replacing formation water resistivity and finally proves the feasibility and simplicity of the discussed saturation model.

In spite of the convenience on the structure and operation led by the saturation formula model that is discussed in this paper, there are still lots of deficiencies. For instance, average value of spontaneous potential is taken in this paper to eliminate the influence of spontaneous potential abnormal value with some useful information being discarded which need further study.

\section{Acknowledgements}

This work is Supported by The Yangtze Youth Fund Grant (No.2015cqn31).

\section{References}

[1] Zhuowu Che. Well Logging Data Analysis Manual [M]. Petroleum Industry Press 2003.

[2] Dewitte L. A. study of electric log interpretation methods in shalyformation [J]. AIME, 1955, 204-206.

[3] Simandoux P. Dielectric mesurements of porous media: Application to measurement of water saturations, study of the behavior of argillaceous formations [J]. Revue de L Institut Franais du Petrole, 1963: 65-68. 
[4] Ning Li. The General Form and Optimum Function Type of Resistivity-Porosity and Resistivity-Oil (gas) Saturation ( II ) [Z]. Beijing SEG Chinese Petroleum Society 1993: 54-56.

[5] Poupon A, Loy M E, Tixer M P. A contribution to electric log interpretation in shaly sands [J]. AIME, 1954, 135-138.

[6] Wanxue Jing, Yongji Chen. On the Original Physical Model of Archie Formula [J]. Well Logging Technology, 1997

[7] Liqiang Sima. Application Technique of Logging Geology [M]. Beijing: Petroleum Industry Press, 2002.

[8] Ping Xu, Yigang Wang. Exploration and Development Research Institute of Liaohe Oilfield Branch Science \& Technology Report on Shu3 Area Comprehensive Adjustment Scheme [R]. Liaohe oilfield Development, 2000.

[9] Daopin Li. Oilfield Development of Low-permeability Sandstone [M]. Beijing: Petroleum Industry Press, 1997.

[10] Zehan Chu. Principle of Acoustic Logging [M]. Beijing: Petroleum Industry Press, 1987.

[11] Qinggeng Zhang. Electrical Logging (Volume One) [M]. Beijing: Petroleum Industry Press, 1987. 